\title{
Research on the Innovation of Talent Training Model in Higher Vocational Colleges with Professional Quality as the Core
}

\author{
Ning Han, Yong Zhang \\ Wuxi Vocational College of Science and Technology, Wuxi, China
}

Email address:

hannew@126.com (Ning Han)

To cite this article:

Ning Han, Yong Zhang. Research on the Innovation of Talent Training Model in Higher Vocational Colleges with Professional Quality as the Core. Science Journal of Education. Vol. 9, No. 3, 2021, pp. 96-103. doi: 10.11648/j.sjedu.20210903.14

Received: April 21, 2021; Accepted: May 19, 2021; Published: May 24, 2021

\begin{abstract}
With China entering a new stage of development, industrial upgrading and economic restructuring are accelerating, the demand for technical skilled personnel in all walks of life is becoming more and more urgent, and professionalism has become the core competitiveness of graduates of vocational colleges. Starting from the relationship between professional quality and talent training, this paper analyzed and expounded the significance of strengthening professional quality in higher vocational colleges for students, schools and society; studied the problems existing in the traditional talent training model of higher vocational colleges. This paper proposes that the innovation of talent training mode should make it clear that professional quality is the core, set talent training objectives and improve talent training programs according to the demand of economic and social development. We should scientifically design the Curriculum system. Teaching system and Evaluation system of talent cultivation on the basis of following the law of education; combine the job needs and students' personality characteristics, expand the multiple training path, and implement the student-centered personalized training; comprehensively improve the students' overall quality and ability level, and ultimately enable students to correctly choose the most suitable path to success.
\end{abstract}

Keywords: Professionalism, Higher Vocational Education, Talent Training Mode

\section{Preface}

\subsection{Research Background}

Vocational education is related to the overall situation of social and economic development, and shoulders the important task of training front-line technical and skilled talents for production, construction, service and management. From the current global situation, although China has become the second largest economy in the world, compared with developed countries, there is still a certain gap in the number of skilled talents, education time, innovation ability, professional quality, etc. in terms of talent training. Higher vocational education has a long way to go.

Vocational education mainly cultivates workers and technical talents who have a certain level of education and professionalism and can adapt to the needs of professional posts. In the critical period of economic and social transformation and upgrading, the survival of the fittest in the market environment, not only more and better skilled talents are needed, but also higher and higher requirements are put forward for the professional quality of skilled talents.

"National medium and long term education planning outline and 2021 reform and development points of higher education" clearly points out that we should follow the law of education and talent growth, deepen education and teaching reform, innovate education and teaching methods, explore a variety of training methods, and form a situation in which all kinds of talents emerge in large numbers and top-notch innovative talents constantly emerge. Standardizing the whole process of talent cultivation and accelerating the cultivation of technical talents with high professional quality have become the inevitable choice of talent cultivation in higher vocational colleges. 


\subsection{Core Concepts}

\subsubsection{Professionalism}

Professionalism has a relatively fixed component, and shows the importance of relative stability characteristics. The "iceberg model" proposed by the famous American psychologist McLellan divides the different expressions of individual qualities into "above the iceberg" and the deep "below the iceberg" on the surface. Among them, the "iceberg above" includes basic knowledge, basic skills, is the external performance, is easy to understand and measure the part, relatively easy to change and develop through training. The "below iceberg" includes social roles, self-image, traits and motivations, which are intrinsic and difficult to measure, and are not easily changed through outside influences, but play a key role in people's behavior and performance. In Professional Quality, San Francisco defines professionalism classically, "Professionalism is the code of conduct that human beings must abide by in social activities, the inherent requirement of the profession, and the comprehensive quality that a person manifests himself in the course of his or her career." [1]

From the content point of view, professional literacy contains three levels of content: First, professional professional quality, including professional knowledge, professional ability, professional emotion, professional value, professional ethics and other qualities; Second, universal professionalism, is engaged in any profession should have, including physical and mental health, communication, digital applications, information technology applications, teamwork, problem solving, self-learning and management and other qualities; Third, the development of professional quality, including continuing learning, professional debugging and development, innovation and creation and other qualities.

\subsubsection{Talent Development Model}

For the first time, the education administrative department made a direct statement on the connotation of "talent training mode", which is pointed out in the document "Opinion on deepening teaching reform and cultivating high-quality talents to meet the needs of the 21 st century" issued by the
Ministry of Education in 1998, stating that "the talent training model is the knowledge, ability and quality structure that schools construct for students, and the way to realize it, which fundamentally defines the characteristics of talents and embodies educational ideas and concepts. " [2]

Talent training model of Vocational Education in China is from the 1950s, from the model of the former Soviet Union, before the $1980 \mathrm{~s}$ and ordinary higher education indiscriminately reflected in the emphasis on knowledge, light ability of the "knowledge-based" characteristics. In the 1990s, drawing on the practice of developed countries, we turned to the "capacity-based" model, but gradually exposed the disadvantages of paying attention to behavior, neglecting moral character, students' creative ability and poor social adaptation. In the 21 st century, under the background of China's innovation-driven development strategy, the reform of talent training model of "career standard" and "personality standard" has been changed, emphasizing that the goal of talent training is also changed from "applied" talent training to "innovative" talent training. [3] At present, the reform of vocational education talent training model does not pursue norms and systems, because of the different definitions of the connotation and extension of "talent training mode", there may be cross-coexistence between different "models", such as "Order Form" model may also be " $2+1$ " "Through training" "Double-combination"and other models. The diversified training model of vocational education talents reflects the practical motivation and trend of vocational education reform and innovation. [4]

\subsection{Research Status}

\subsubsection{Domestic Research Status}

\section{a. Literature retrieval survey}

According to the "professional literacy and talent training model" in CNKI for literature retrieval, the annual distribution of the literature results is shown in Figure 1. It can be seen that the research of professional literacy as the core talent training model has become a research hot topic in academia since 2007 .

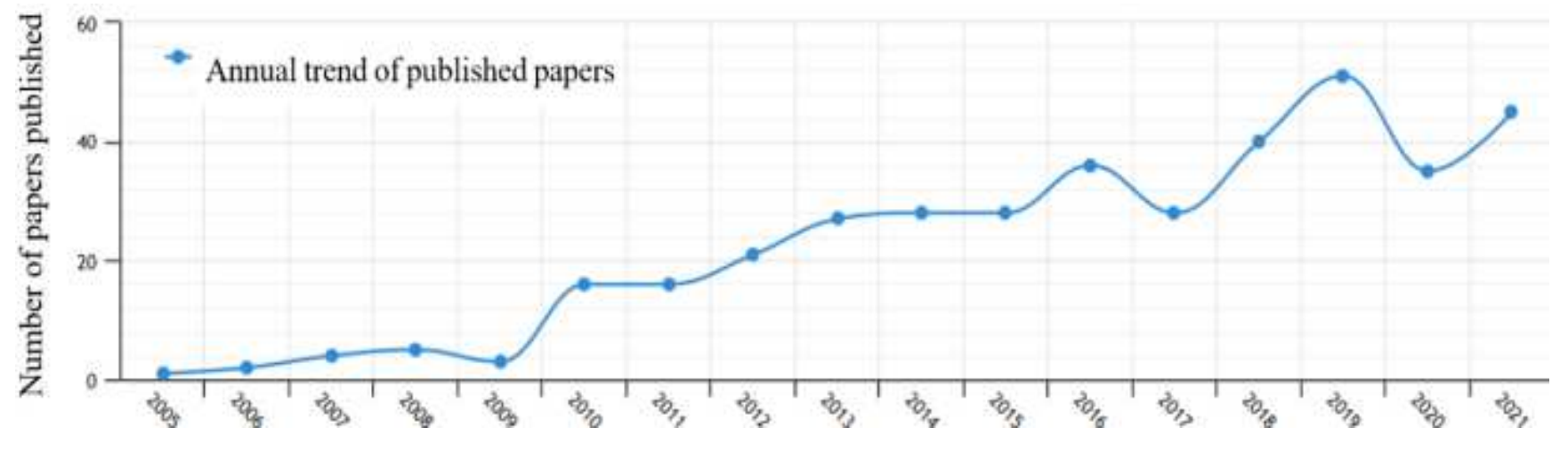

Figure 1. The Literature Trend of the Research on Professional Quality and Talent Training Model.

By further sorting out the theme-words and keywords of relevant literature, we can get the distribution of the key issues of professional quality and talent training mode, and the results are shown in Figure 2: 


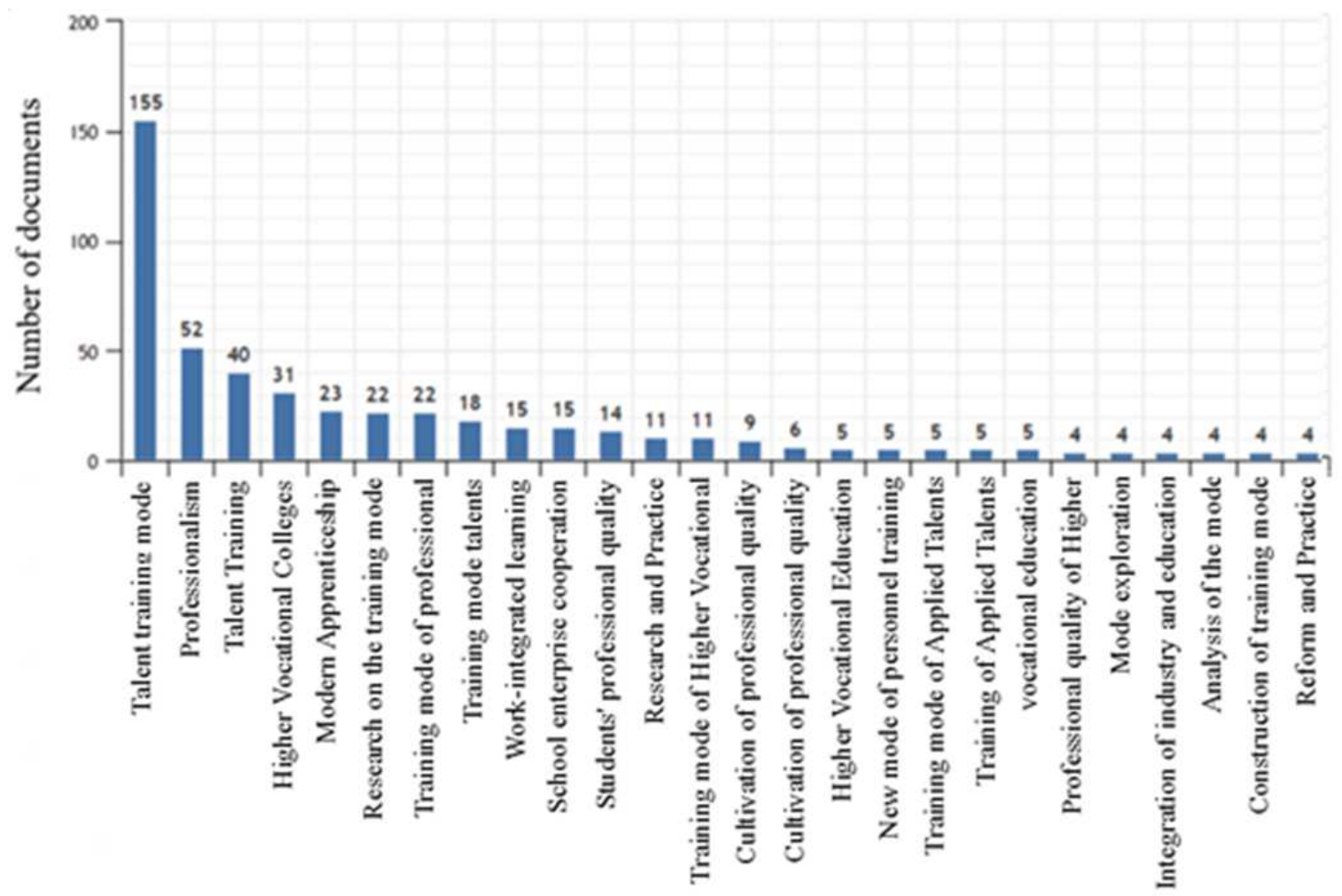

Figure 2. Distribution of professional quality and talent training model research.

It can be seen that the talent training model, talent training, school-enterprise cooperation, higher vocational colleges, combination of work and study, modern apprenticeship and applied talents are all the focal points of domestic research.

b. Previous materials

Along with the different research stages of talent training in higher vocational colleges, professional literacy has also gone through different development stages. Occupational literacy continues to penetrate, forming a specific relationship between vocational literacy and the training model of higher vocational talents at different stages. In previous studies, the research on the relationship between professional literacy and higher vocational talent training model is not in-depth.

The main research can be divided into Training model of comprehensive professional quality, Cultivation of integrated talents, The reform of personnel training model from the perspective of professional quality and other aspects. In "Several Theoretical Points of Higher Vocational Curriculum Reform", Xinxiang Lv clearly pointed out that students' vocational quality education is of great significance to the construction of higher vocational curriculum goals. It is necessary to link vocational quality education to higher vocational curriculum goals and expand professional positions to the key links of their careers. [5] Some scholars have proposed that the implementation and goals of higher vocational courses should be "professional preparation" and should be related to vocational education. In "Exploration of Professional Talents Training in Higher Vocational Colleges", Jianshe $\mathrm{Wu}$ correlated professional literacy with the specific courses of vocational training in higher vocational colleges, and focused on the relationship between professional literacy and "cooperative education"in higher vocational courses. [6] Hui Wan and Qinwu Rao conducted effective discussions on the relationship between professional literacy and higher vocational students' talent training. At the same time, they have effectively penetrated the concept of vocational literacy into the training of vocational students, and put forward a series of vocational literacy development for higher vocational students. They talked about the impact of professional literacy on higher vocational courses in some degree. [7]

\subsubsection{Research Status Abroad}

The related research on professional literacy in foreign countries preceded that in China. After the 1990s, many factions gradually formed, mainly focusing on the scattered research of professional literacy and vocational curriculum system. It was American psychologist John Flenegan who introduced vocational literacy into higher education. He put forward the critical event analysis method in 1941, which was regarded as the beginning of vocational literacy education research and was soon introduced into higher education. Afterwards, San Francisco made a classic definition of professionalism in "Professionalism". Psychologists Sapa and Chiklin respectively put forward the "five stages of human occupation" and the "seven-faced theory" of professional literacy. The relationship between professional literacy and education has gradually become closer and deeply related. The dual education model of "doing by learning, learning by doing"in Germany and the "vocational education focusing on core competence 
education" put forward by the United Kingdom has further refined vocational education from the generalized higher education field to vocational education. [8]

To sum up, it can be seen that, regardless of whether it is domestic or foreign, although the research on professional quality and talent training models is involved, it has not yet formed a comprehensive overall research. To a certain extent, its research paradigm is a theoretical retrospective guided by practice. As far as the research method is concerned, it is mainly the induction method based on the summary of experience. The professional quality has not formed the wind direction function of guiding the education and teaching activities in the reform of the higher vocational talent training model.

\section{Research Ideas and Methods}

\subsection{Research Ideas}

The talent training system is a huge concept system, and it is very important to construct a complete and scientific talent training system in the core literacy training of higher vocational students. This paper follows the concept of deepening thought and problem-oriented research to carry out research, according to the "problem attribution, interpretation of the original rationale, the status quo review, the initial structure of the system, practical demonstration" of the specific thinking to carry out specific research, in the summary, discovery, innovation out of a professional quality as the core of the training and innovation model of higher vocational education, for the new era of higher vocational education reform and development to provide constructive experience and advice.

\subsection{Research Methods}

Using the theories and methods of higher education, higher education management, educational psychology, university curriculum and teaching theory, and adopting the interdisciplinary integrated analysis, this paper adopts the following research methods:

a. Literature analysis method

By collecting, reading and analyzing the relevant literature at home and abroad, this paper sorts out the theoretical fulcrum and thinking framework of the research, summarizes the relationship and development trend between talent training mode and professional quality in higher vocational colleges, and provides a theoretical basis for optimizing and innovating talent training mode in higher vocational colleges.

b. Investigation and research method

Aiming at the research goal, this paper makes a field survey on the cultivation of Vocational Students' professional quality, through a detailed analysis of the characteristics of students' differences, find out the problems, and analyze the reasons, and then a comprehensive and in-depth understanding of the current situation of talent training in higher vocational colleges.

c. Action Research method

Combined with the characteristics of talent cultivation in higher vocational colleges, this paper puts forward the optimization scheme of talent cultivation system, summarizes the reform path of talent cultivation mode, and carries out action research in pilot schools, summarizes and accumulates experience, and then promotes it to a wider range.

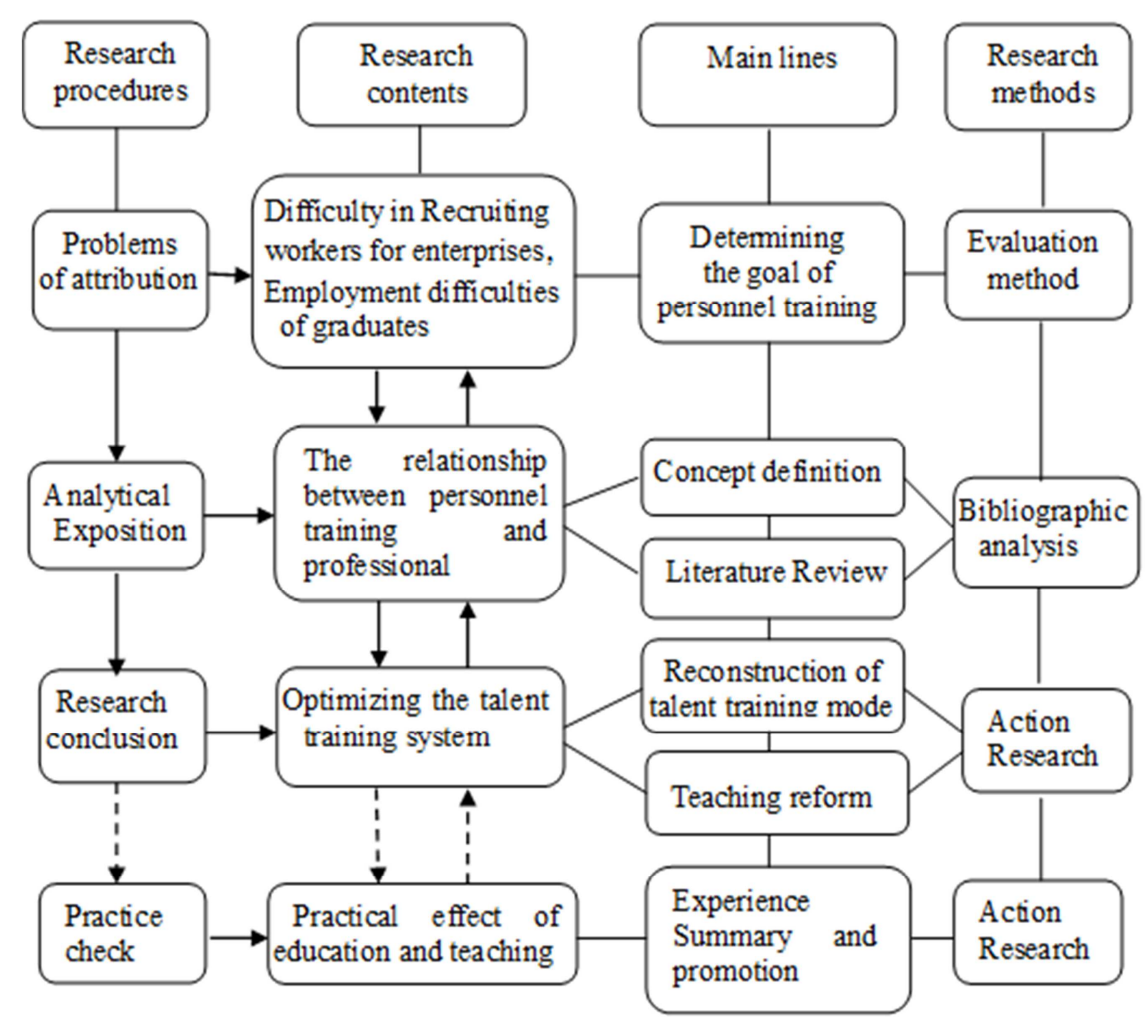

Figure 3. Study ideas and method diagrams. 


\section{Result}

\subsection{Professional Quality Should Be the Core of Talent Training in Higher Vocational Colleges}

\subsubsection{Professional Literacy is the Basis of Higher Vocational Students}

Marinka Kuijpers and Frans Meijers say in their paper that 100 percent of the job requirements for higher education in the Netherlands clearly identified the required education, 50 percent stated the necessary work experience, and 20 percent outlined the priority interests for the position 30 years ago. Today, all job requirements include general competencies, half of which are related to employability and personal development, including flexibility, learning ability, reflectivity, and initiative. [9]

A number of domestic survey results in recent years also show that the biggest problem for vocational college graduates after entering enterprises is not the lack of knowledge and skills, but the lack of professionalism. Many entrepreneurs mentioned in the interview that the most important value for enterprises to vocational college students is not technical skills, but attitude, sense of responsibility and other professional qualities. It can be seen that in order to realize the high quality and sustainable development of higher vocational college graduates, it is necessary to explore the potential of students, improve their post adaptability, learning ability, innovation ability, enhance their self-confidence, sense of responsibility, and cultivate and strive for development opportunities for them. Therefore, good professional quality is the foundation and guarantee of vocational college students' career.

\subsubsection{Taking Professionalism as the Core Is The Objective Demand for the Talent Training in Higher Vocational Colleges}

College is a decisive stage in the formation of one's world outlook, outlook on life and values. The college should focus on cultivating students' core professional quality. Professional quality includes the spirit of dedication, the quality of cooperation and hard work, the loyalty to the enterprise, etc.. It is the symbol and performance of the overall development of higher vocational students. It's very important for improving students' personal quality, maintaining good interpersonal relationship, improving work and life quality. Therefore, it is not only the objective demand of social development in the new era, but also the inevitable requirement of talent cultivation in higher vocational colleges to integrate the cultivation of professional quality into the whole process of talent cultivation.

\subsubsection{Optimizing the Talent Training Model in Higher Vocational Colleges Is the Inevitable Trend of Cultivating Great Power Craftsmen}

For a long time, the goal of talent training in higher vocational colleges is to cultivate technical talents. The employment goal of graduates is mainly the operators, installers, debuggers, waiters and other low-level staff in the production line. In 2019, "the Implementation Plan of National Vocational Education Reform" points out that the development of higher vocational education is an important way to optimize the structure of higher education and cultivate great power craftsmen and skilled craftsmen. Higher vocational schools should cultivate high-quality technical and skilled talents to serve regional development. To achieve such training objectives, we need not only to improve the teaching level, enrich the curriculum type, but also need to optimize the teaching methods, improve the evaluation system. Through the guidance of scientific ideas, we should stimulate students' initiative of self-learning, self-education and self-improvement, and improve their comprehensive quality while improving their technical skills.

\subsection{Innovative Ideas of Talent Training Model with Professionalism as the Core in Higher Vocational Colleges}

\subsubsection{Establish and Strengthen the Value Orientation of "Professional Quality Should Be the Core of Talent Training in Higher Vocational Colleges"}

Talent training system is a complicated system project. At present, in the process of talent cultivation of higher vocational education in China, there are still some problems, such as the homogenization of curriculum structure, the old way of talent cultivation, the single way of education and teaching, the lack of humanistic quality of students and so on. These are the bottleneck problems that restrict the graduates of higher vocational colleges to become high-quality technical talents. According to "Opinions of the Ministry of education on comprehensively improving the teaching quality of higher vocational education", all higher vocational colleges should take students' integrity ability, responsibility consciousness, law-abiding consciousness and learning ability as the main training objectives, and cultivate a group of high-quality skilled talents. Therefore, higher vocational colleges must have clear and scientific talent training objectives, which not only determines whether higher vocational graduates can adapt to the job demand, but also determines the sustainable development of higher vocational education. On the premise of making it clear that the talent training mode takes professional quality as the core, we should systematically arrange the construction of curriculum system, education and teaching methods, expand diversified talent training paths, and innovate and improve the talent training mode, which can improve the employment rate and quality of graduates, cultivate more high-quality technical and skilled talents, and provide reference for further improving the work level, so as to promote the high-quality and high-level development of the school.

\subsubsection{Further Improve the Talent Training Program of Each Specialty According to the Talent Training Objectives}


Vocational education should make a "natural person"or "biological person"become a professional person needed by the society, not just a pure professional person, but a social person who needs to survive and develop. [10] Technical and skilled personnel with high professional quality not only has a solid professional foundation and strong hands-on ability, but also can quickly adapt to the needs of the station and maintain the trend of progress. To achieve this training objectives, higher vocational colleges should adhere to the orientation of market orientation, service development and employment promotion, and improve the education mechanism of combining morality with technology. The talent training program of each specialty should be close to the demand of economic and social development for talents, and fully mobilize the enthusiasm, initiative and creativity of students in combination with the demand of jobs and the personality characteristics of students. The specialty setting and training objectives should be highly career specific. We should not only attach importance to the standardized technical skills training of students, but also attach great importance to the personalized training with career development as the value orientation. It is necessary to teach students in accordance with their aptitude, implement student-centered personalized training, and design diversified curriculum system according to the training needs of different types of students, so as to promote everyone's success. We should design teaching according to students' personality and guide them to study and practice according to their actual ability. It is necessary to set up credits scientifically so that students have the time, conditions and possibility to plan their own high-quality development goals scientifically according to their own personality characteristics and advantages, and choose the most suitable way for themselves in employment, further education and entrepreneurship.

\subsubsection{Build the Teaching System of Higher Vocational Education with Professional Quality as the Core}

Huang Yanpei, known as the pioneer of vocational education, once pointed out, "Vocational education takes occupation as the method and occupation as the purpose."The purpose of vocational education is to "seek the development of personality, prepare for personal livelihood, and serve the society for the individual." [11] In order to train high-quality technical and skilled personnel, higher vocational colleges should scientifically design the curriculum system, teaching system and appraisal system of talent cultivation, and systematically arrange the education and teaching activities and methods according to the needs of the industry for professional quality and ability and on the premise of following the education rules. According to the nature and characteristics of the pre-set positions for students, higher vocational colleges should help students to lay a solid foundation for development through offering public courses, help students to establish professional consciousness through offering professional basic courses, improve students' technical level through offering professional core courses, and improve students' comprehensive quality through offering general elective courses. Vocational education should not only teach the basic professional and technical knowledge and operational knowledge, but also arrange the relevant knowledge needed to adapt to the progress of science and technology and the optimization and upgrading of industrial structure; not only teach students the ability of on-site technical operation, organization and coordination, but also exercise their independent learning ability, social communication ability and innovation and entrepreneurship ability. It is necessary not only to make students have ideological and moral cultivation and professional ethics, but also to help them develop the personality quality of honesty, hard work and innovation. In this way, higher vocational students can develop and improve the spirit of scientific and technological innovation and humanistic spirit. They can achieve high-quality employment, and can maintain sustainable development and progress.

\subsubsection{Expand the Multiple Training Path for the Purpose of Improving the Professional Quality of Higher Vocational Students}

As early as 1972, UNESCO noted in "Learning to Survive-Today and Tomorrow in the Education World" that "the purpose of education is to develop the ability to move as much as possible through various occupations and to always stimulate their desire to learn and train themselves." [12] In order to cultivate high-level practical talents to meet the needs of all walks of life, higher vocational colleges should earnestly implement the concept of "student-centered", establish the concept of "everyone has the opportunity, everyone can become a talent". We should not only care and guide students in politics, study, employment, psychology and life, but also guide students to correctly deal with all kinds of relationships and solve the problems encountered in learning, help students go to the society smoothly. Higher vocational colleges should combine the actual situation of schools, students and the needs of enterprises to innovate the ways and methods of cultivating professional quality, fully explore the advantages and potential of students, and implement student-centered personalized training, so that students can improve their comprehensive quality on the basis of establishing a relatively complete knowledge system and a more professional technical system and training more skilled technical skills. Vocational colleges should bring professional quality into the education system. So, in addition to teaching in class, we should also fully explore and make use of the functions of ceremonies, practical training, competition activities, social services and other student activities to cultivate students' professional quality. We should build a healthy and progressive campus culture, introduce and integrate profound local culture and excellent and advanced enterprise culture to educate and influence students, internalize the comprehensive quality with professional quality as the core into students' consciousness and belief, and transform it into students' workplace competitiveness. 


\section{Discussion}

Researchers such asBenner PandDreyfus SEhave found that a person's career growth follows a logical pattern of development from beginner to expert (i.e., beginner, senior beginner, capable, skilled, expert). Similarly, the growth of skilled personnel is also in line with the development law from beginner to expert, in which each stage of career development has different requirements for knowledge, ability, attitude, values and so on. That is to say, the development of skilled personnel from the lower stage to the higher stage is not a simple process of knowledge accumulation, but from the completion of simple tasks to the completion of relatively complex tasks of professional development process, accompanied by knowledge, ability, emotion, attitude, values and other comprehensive quality growth and realization. [13]

This paper expounds the significance of professionalism to students in vocational colleges and vocational colleges, and also makes some research on the optimization of the talent training system in vocational colleges, but these jobs are not enough. For example, in the process of perfecting the personnel training system, how to run the concept of "occupation quality as the core" in teaching practice and examine it; how to set up or adjust the curriculum, so that students can really master the basic theoretical knowledge and effectively improve their professional quality; how to set up the selection criteria of teachers in order to provide qualified teachers for talent training; In school local cooperation and school enterprise cooperation, how to fully mobilize and play the role of both sides to form a joint force and make the talent training system form a complete closed loop, and so on. In the next step, the author will continue to study the relevant issues, hoping to provide more scientific and effective information and support for the talent training model of higher vocational colleges.

\section{Conclusion}

Professional quality is the cornerstone of the professional development of higher vocational students, is the inevitable requirement for higher vocational colleges to improve the quality of running schools, but also the social development needs of the new era. The innovation of the talent training mode of higher vocational colleges should start from paying attention to the value orientation; establish and strengthen the understanding that "the training of talents in higher vocational colleges should take professional accomplishment as the core"; further improve the talent training program so that the talent training goal is closely related to the demand for talents in economic and social development; design the Curriculum system, Teaching system and Evaluation system of talent training scientifically, design and arrange public courses, professional basic courses, professional core courses and general elective courses, so as to enable students to establish a relatively complete knowledge, professional technical system and acquire more skilled skills; implement the individualized training of "student-centered", comprehensively improve the overall quality of students through diversified training paths such as ceremony, practical training, competition activities, social services and other student activities; ultimately makes students choose the most suitable growth path in employment, continuing education and entrepreneurship.

\section{Acknowledgements}

This article is supported by Wuxi Science and Technology Development Funding Project: Study on the Cases of Constructing Technology Innovation System Based on Deep Integration of Industry and Education (Project No.:WX0306I023604200037PB) and The Key Project of Philosophy and Social Science Research in Colleges and Universities in Jiangsu Province: Research on Promoting mechanism of Industry Education Integration Strategy (Project No.: 2019SJZDA045).

\section{References}

[1] Qiang Nie. Cross-boundary and integration: research of higher vocational curriculum based on professional quality [D]. Southwest University, 2017: 8 (in Chinese).

[2] Xianjun Liu, Hongfu Wu. The connotation, restriction and outlet of the reform of personnel training mode [J]. China Higher Education, 2009, (12): 10-13. (in Chinese).

[3] Shihua Luo. On the construction of innovative talents training mode in higher vocational education in China [J]. Journal of central China Normal University (Humanities and Social Sciences Edition), 2013, (4): 140. (in Chinese).

[4] Jie Lan. Review and Prospect: A review of the research on the talent training mode of Vocational Education [J]. Vocational Education Forum, 2015, (23): 53. (in Chinese).

[5] Xinxiang Lv. Several Theoretical Points of Curriculum Reform in Higher Vocational Education [J]. China University Teaching, 2002, (10): 30-33. (in Chinese).

[6] Jianshe Wu. Exploration of Cultivating Professional Talents in Higher Vocational Colleges [J]. Journal of Huzhou Vocational and Technological College, 2003, (01): 57-60. (in Chinese).

[7] Hui Wan, Qinwu Rao."Research on the Deficiency and Reconstruction of Vocational Quality Training of Post-90s" Vocational Students [J]. Journal of Vocational Education, 2011, (34): 76-78. (in Chinese).

[8] Qiang Nie. Cross-boundary and integration: research of higher vocational curriculum based on professional quality [D]. Southwest University, 2017: 17 (in Chinese).

[9] Marinka Kuijpers, Frans Meijers. Learning for now or later? Career competencies among students in higher vocational education in the Netherlands [J]. Studies in Higher Education, 2012, (37): 449-467.

[10] Dayuan Jiang. Essentials of Vocational Education [M]. Beijing: Beijing Normal University Press, 2017: 10 (in Chinese). 
[11] China Vocational Education Society. Collected works of Huang Yanpei on Education (Volume I) [M]. Beijing: China literature and history press, 1995: 213 (in Chinese).

[12] UNESCO. Learning to survive: today and tomorrow in the world of education. Trans. East China Normal University. Shanghai Translation Press, 1982: 547 (in Chinese).
[13] Lei Sang. Research on Vocational Core literacy and its cultivation of higher vocational students [D]. Nanjing Normal University, 2020: 40 (in Chinese). 